\title{
Clinical Characteristics for the Relationship between Type-2 Diabetes Mellitus and Cognitive Impairment: A Cross-Sectional Study
}

\author{
Yi Zhou ${ }^{1}$, Rong Fang ${ }^{1}$, Li-Hua Liu ${ }^{2}$, Sheng-Di Chen ${ }^{1 *}$, Hui-Dong Tang ${ }^{{ }^{*}}$ \\ ${ }^{1}$ Department of Neurology, Rui Jin Hospital affiliated to Shanghai Jiao Tong University School of Medicine, \\ Shanghai, 200025, China \\ ${ }^{2}$ Department of Neurology, the People's Hospital of Jurong City, Zhenjiang, 212400, China
}

[Received Agust 14, 2014; Revised October 3, 2014; Accepted October 4, 2014]

\begin{abstract}
We explored the potential differences in cognitive status, lipid and glucose metabolism, ApoE\&4 alleles and imaging between diabetic and non-diabetic subjects. 83 subjects with normal cognitive function and 114 mild cognitive impaired patients were divided into four groups by history of diabetes. General demographics was collected from all participants followed by MRI scan, biochemical examinations and a series of neuropsychological tests. Student's t test, multiple regressions and one-way ANOVA were applied to investigate the differences between groups. Comparing diabetic patients with non-diabetic subjects in the mild cognitive impaired group, we found several decreased items in recall of three words in MMSE $(p=0.020)$, AVLT and SCWT $(p<0.050)$. The multiple linear regression revealed that two-hour glucose level $(\mathrm{B}=-0.255, p<0.001)$ and fasting $\mathrm{C}$-peptide $(\mathrm{B}=-0.466$, $p=0.001$ ) had negative effects on the score of MMSE. In addition, diabetic patients treated with insulin and other diabetes medication performed better in part of the AVLT $(p<0.050)$ compared to patients with insulin treatment or oral antidiabetic medication only. Patients with metformin medication had a better memory outcome compared to patients with sulphonylurea medication in the AVLT long delay free recall $(p=0.010)$. These findings show that patients of mild cognitive impairment with diabetes mellitus have a worse outcome in attention, information processing speed and memory compared to non-diabetic patients. Higher two-hour glucose level and C-peptide level may be risk factors for severe cognitive impairment in type- 2 diabetes mellitus patients. The results of this study also suggest that medication may have effects on cognitive function.
\end{abstract}

Key words: Type-2 diabetes mellitus, mild cognitive impairment, C-peptide, blood glucose

The incidence of type-2 diabetes mellitus (T2DM) in China has dramatically increased in the last decade. Besides the well-known connection between T2DM and peripheral nervous system disease, the diabetes-induced lesions in the central nervous system (CNS), such as cerebrovascular disease and cognitive dysfunction, are receiving increased attention. Several epidemiological studies have found that T2DM is an independent risk factor for both Alzheimer's disease (AD) and vascular dementia (VaD) $[1,2]$. In addition, further research has shown that T2DM may also exercise influence on the prevalence of mild cognitive impairment (MCI), which is considered a pre-clinical stage of dementia. In Luchsinger and colleagues' study [3], the results indicated that diabetes mellitus is related to a relatively higher risk for all causes of MCI (about 1.5 fold). In another recent metaanalysis report, diabetes was shown to have higher risk for any dementia and MCI (1.46 for $\mathrm{AD}, 2.48$ for $\mathrm{VaD}$ and 1.21 for MCI) [4].

The present studies have confirmed that T2DM is a robust risk factor for cognitive dysfunction. However, the precise mechanisms remain to be elucidated [5]. A wide range of metabolic and vascular disturbances have been proposed to explain the underlying mechanisms of

*Correspondence should be addressed to: Sheng-Di Chen and Hui-Dong Tang, Department of Neurology, Rui Jin Hospital, Shanghai Jiao Tong University, Shanghai, China. Email: tanghuidong@medmail.com.cn or chen_sd@medmail.com.cn. 
T2DM-related cognitive impairment including impaired neurogenesis and blood-brain barrier (BBB), hyperglycemia and hypoglycemia, inflammatory and oxidative stress, microvascular and macrovascular dysfunctions, a disturbance in the insulin signaling pathways and the altered metabolism of beta-amyloid and tau [6-8]. To date, there are no explicit treatments to help ameliorate cognitive decline in patients with DM, but an emerging awareness of brain protection in diabetic treatments and diabetes management have seen an increase. Some studies have reported a benefit of improved cognition by the effect of blood glucose control while others indicated the efficacy of lipid-lowering therapy $[9,10]$. Our study aimed to analyze the differences in neuropsychology, glucose and lipid metabolism, ApoE 44 genotype between MCI patients and normal controls with and without T2DM and to explore the possible role of the relevant factors in the pathogenesis of cognitive dysfunction. We hope that the hypothetical mechanisms underlying T2DM-related cognitive impairment combined with clinical evidence will provide a better perspective of diabetic treatments.

\section{MATERIALS AND METHODS}

\section{Subject}

All participants met the following criteria: 1) Male or female in the 50-95 age group 2) Have a certain level of education (at least 6 years), able to complete the neuropsychological tests 3) No history of neurologic or psychological illness 4) No abnormal results of thyroid hormones, vitamin $\mathrm{B} 12$, and folate. 5) No history of cardiovascular or cerebrovascular disease; Hachinski Ischemic Score $\leq 46$ ) No metal implants, able to complete the MR examinations and no evidence of cortical infarcts, hemorrhage, or structural brain disease other than atrophy, lacunes, or white matter lesions. The subjects were distributed into diabetic and non-diabetic groups using the WHO report for diagnosis and classification of diabetes mellitus in 1999 [11]. All the MCI patients were diagnosed following the Peterson clinical criteria proposed in 1999 [12].

According to the criteria mentioned above, a total of 83 non-cognitive impaired subjects were recruited in our study, 43 of which were with T2DM (22 males and 21 females) and the rest were normal controls without T2DM (23 males and 17 females). There was no significant difference in age $(p=0.063)$ and most of the biochemical outcomes except for plasma glucose metabolism [fasting plasma glucose (FPG), two hour postprandial plasma glucose (2h-PG), and glycated hemoglobin $\left.\left(\mathrm{HbA}_{1} \mathrm{c}\right)\right]$, which differed significantly between these two groups.

In the MCI group, 65 subjects had no history of T2DM
(33 males and 32 females) while another 49 participants had T2DM (24 males and 25 females). No significant difference was found in age $(\mathrm{p}=0.091)$. Plasma glucose metabolism also showed a different trend combined with a slight increase in triglycerides in MCI subjects without T2DM (Table 1).

The study was approved by the Research Ethics Committee of Rui Jin Hospital (affiliated to Shanghai Jiao Tong University School of Medicine, China). Written informed consent was also obtained from each participant.

\section{Laboratory measures and genotyping}

Plasma glucose concentrations (FPG, 2h-PG, and $\mathrm{HbA}_{1} \mathrm{c}$ ) and synchronous insulin [fasting insulin (FINS), and two hours insulin (2h-INS)] as well as fasting C-peptide (FCP), plasma lipid content [total cholesterol (TC), triglyceride (TG), high-density lipoproteins (HDL), and low-density lipoproteins (LDL)] were collected and analyzed by an automatic biochemical analyzer in one week after the clinical and neuropsychological assessment. Apolipoprotein $\varepsilon 4$ ( $A P O E \& 4)$ genotyping was performed by polymerase chain reaction-restriction fragment length polymorphism assays (PCR-RFLP) as described in our previous study [13].

\section{Magnetic Resonance Imaging (MRI)}

We measured the interuncal distance (IUD) and the intracranial width (ICW) at the suprasellar stern level from the axial MR scans acquired on 1.5 T GE Sign Horizon for all the subjects and then calculated the IUD/ICW according to previous reports $[14,15]$ (Figure $1)$.

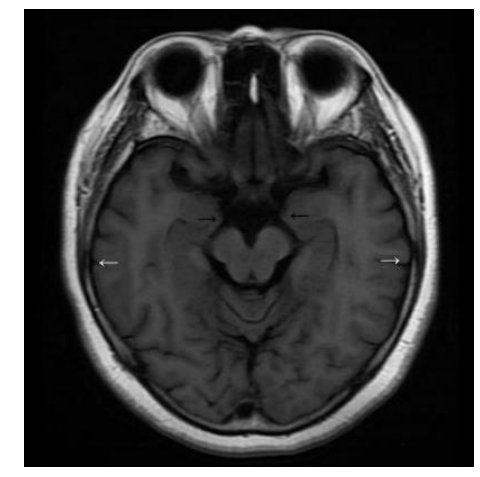

Figure 1. Brain MRI: measurement of the interuncal distance (IUD) and the intracranial width (ICW). IUD and ICW were acquired at the suprasellar stern level from the axial T1 images. The measurement of IUD is indicated by the black arrows and the ICW by the white arrows. 
Table 1A. Comparison of demographic information between control and mild cognitive impairment groups

\begin{tabular}{|c|c|c|c|c|c|}
\hline & $\begin{array}{c}\text { Total } \\
\text { number }\end{array}$ & Male (female) & Age (yrs) & $\begin{array}{c}\text { Education } \\
\text { (yrs) }\end{array}$ & $\begin{array}{c}\text { APOE } \& 4(+) \text { carriers } \\
(\%)\end{array}$ \\
\hline \multicolumn{6}{|l|}{$\mathrm{NC}$} \\
\hline Non-DM & 40 & $23(17)$ & $64.45 \pm 8.98$ & $12.69 \pm 3.39$ & 25.0 \\
\hline DM & 43 & $22(21)$ & $68.42 \pm 9.10$ & $12.77 \pm 3.10$ & 18.6 \\
\hline$p$ & & 0.563 & 0.063 & 0.925 & 0.434 \\
\hline \multicolumn{6}{|l|}{ MCI } \\
\hline Non-DM & 65 & $33(32)$ & $66.12 \pm 9.36$ & $12.81 \pm 12.88$ & 31.4 \\
\hline DM & 49 & $24(25)$ & $68.68 \pm 8.23$ & $11.78 \pm 3.76$ & 24.5 \\
\hline$p$ & & 0.850 & 0.091 & 0.963 & 0.537 \\
\hline
\end{tabular}

Table 1B. Comparison of glucose metabolism between control and mild cognitive impairment groups

\begin{tabular}{lllllll}
\hline & $\begin{array}{l}\text { FPG } \\
\mathbf{m m o l} / \mathbf{L}\end{array}$ & $\begin{array}{l}\mathbf{2 h}-\mathbf{P G} \\
\mathbf{m m o l} / \mathbf{L}\end{array}$ & $\begin{array}{l}\text { FINS } \\
\boldsymbol{\mu l} \mathbf{~} / \mathbf{m l}\end{array}$ & $\begin{array}{l}\mathbf{2 h}-\mathbf{I N S} \\
\boldsymbol{\mu l ~ U} / \mathbf{m l}\end{array}$ & $\begin{array}{l}\mathbf{H b A}_{\mathbf{1}} \mathbf{c} \\
\boldsymbol{\%}\end{array}$ & $\begin{array}{l}\mathbf{F C P} \\
\mathbf{n g} / \mathbf{m l}\end{array}$ \\
\hline $\mathbf{N C}$ & & & & & & \\
$\mathbf{N o n}-\mathbf{D M}$ & $5.16 \pm 0.89$ & $7.68 \pm 3.73$ & $7.02 \pm 2.94$ & $55.03 \pm 24.24$ & $5.97 \pm 0.33$ & $1.87 \pm 0.23$ \\
$\mathbf{D M}$ & $6.63 \pm 1.23$ & $10.55 \pm 3.27$ & $11.85 \pm 19.42$ & $51.41 \pm 35.39$ & $7.02 \pm 1.71$ & $2.24 \pm 1.35$ \\
$\boldsymbol{p}$ & $<0.001$ & 0.006 & 0.509 & 0.485 & 0.002 & 0.175 \\
$\mathbf{M C I}$ & & & & & & \\
Non-DM & $5.07 \pm 0.60$ & $7.22 \pm 1.26$ & $9.27 \pm 5.97$ & $80.43 \pm 69.19$ & $5.6 \pm 0.82$ & $3.07 \pm 1.13$ \\
$\mathbf{D M}$ & $7.10 \pm 2.10$ & $12.25 \pm 5.83$ & $11.50 \pm 8.15$ & $79.43 \pm 95.28$ & $7.44 \pm 1.55$ & $2.53 \pm 1.78$ \\
$\boldsymbol{p}$ & $<0.001$ & $<0.001$ & 0.555 & 0.817 & $<0.001$ & 0.491 \\
\hline
\end{tabular}

$\mathrm{NC}=$ non-cognitive impairment subjects; Non-DM = non type-2 diabetes mellitus subjects; $\mathrm{DM}=$ type-2 diabetes mellitus subjects; $\mathrm{MCI}=$ mild cognitive impairment subjects; $\mathrm{FPG}=$ fasting plasma glucose $; 2 \mathrm{~h}-\mathrm{PG}=$ two hours postprandial plasma glucose; FINS = fasting insulin; 2h-INS = two hours insulin; $\mathrm{HbA}_{1} \mathrm{c}=$ glycated hemoglobin; FCP $=$ fasting C-peptide

Table 1C. Comparison of lipid metabolism between control and mild cognitive impairment groups

\begin{tabular}{lcccc}
\hline & $\begin{array}{c}\text { TC } \\
\mathbf{m m o l} / \mathbf{L}\end{array}$ & $\begin{array}{c}\text { TG } \\
\mathbf{m m o l} / \mathbf{L}\end{array}$ & $\begin{array}{c}\text { HDL } \\
\mathbf{m m o l} / \mathbf{L}\end{array}$ & $\begin{array}{c}\text { LDL } \\
\mathbf{m m o l} / \mathbf{L}\end{array}$ \\
\hline $\mathbf{N C}$ & & & & \\
$\mathbf{N o n}-\mathbf{D M}$ & $4.49 \pm 0.97$ & $1.31 \pm 0.69$ & $1.32 \pm 0.27$ & $2.80 \pm 0.83$ \\
$\mathbf{D M}$ & $4.89 \pm 0.96$ & $1.84 \pm 1.42$ & $1.39 \pm 0.55$ & $2.97 \pm 0.74$ \\
$\boldsymbol{p}$ & 0.142 & 0.070 & 0.758 & 0.498 \\
$\mathbf{M C I}$ & & & & \\
$\quad$ Non-DM & $5.00 \pm 0.97$ & $1.87 \pm 1.17$ & $1.25 \pm 0.33$ & $2.98 \pm 0.82$ \\
$\mathbf{D M}$ & $4.96 \pm 0.98$ & $1.43 \pm 0.77$ & $1.31 \pm 0.34$ & $3.19 \pm 0.73$ \\
$\boldsymbol{p}$ & 0.741 & 0.042 & 0.649 & 0.186 \\
\hline
\end{tabular}

$\mathrm{NC}=$ non-cognitive impairment subjects; Non-DM = non type-2 diabetes mellitus subjects; $\mathrm{DM}=$ type-2 diabetes mellitus subjects; $\mathrm{MCI}=$ mild cognitive impairment subjects; $\mathrm{TC}=$ total cholesterol; $\mathrm{TG}=$ triglyceride; $\mathrm{HDL}=$ high-density lipoprotein; LDL = low-density lipoprotein 
Table 1D. Comparison of MR scan between control and mild cognitive impairment groups

\begin{tabular}{cccc}
\hline & $\begin{array}{c}\text { IUD } \\
\mathbf{c m}\end{array}$ & $\begin{array}{c}\text { ICW } \\
\mathbf{c m}\end{array}$ & IUD/ICW \\
\hline NC & & & \\
Non- & $2.43 \pm 0.27$ & $12.80 \pm 0.63$ & $0.19 \pm 0.02$ \\
$\mathbf{D M}$ & $2.57 \pm 0.36$ & $12.71 \pm 0.58$ & $0.20 \pm 0.03$ \\
$\mathbf{D M}$ & 0.131 & 0.567 & 0.068 \\
$\boldsymbol{p}$ & & & \\
MCI & & $12.71 \pm 0.72$ & $0.20 \pm 0.31$ \\
Non- & $2.51 \pm 0.41$ & $12.65 \pm 0.60$ & $0.20 \pm 0.03$ \\
DM & $2.50 \pm 0.33$ & 0.667 & 0.895 \\
$\mathbf{D M}$ & 0.880 & \\
$\boldsymbol{p}$ &
\end{tabular}

$\mathrm{NC}=$ non-cognitive impairment subjects;

Non-DM = non type-2 diabetes mellitus subjects;

$\mathrm{DM}=$ type-2 diabetes mellitus subjects;

MCI = mild cognitive impairment subjects;

IUD = interuncal distance;

$\mathrm{ICW}=$ intracranial width

\section{Clinical and neuropsychological assessment}

Clinical and neuropsychological assessments included the Mini-Mental State Examination (MMSE), Auditory Verbal Learning Test (AVLT), Clinical Dementia Rating (CDR), and Stroop Color Words Test (SCWT). We used the Chinese version of the MMSE in our study with cutoff points according to the educational level: 17/18 for illiterates, 20/21 for those with primary school education, and $24 / 25$ for subjects with middle school or higher education [16]. According to the previous study, the AVLT immediate recall (a full score of 36) and long delayed free recall (20 minutes after with a full score of 12) were measured to assess the memory of subjects [17]. In this study, we added another two other components into the evaluation: the AVLT 5-minute recall (a full score of 12) and long delay cued recall. The CDR is a five-point scale with six independent domains (memory, orientation, judgment and problem solving, community affairs, home and hobbies, and personal care) [18]. Normally, CDR-0 connotes no cognitive impairment, CDR-0.5: very mild dementia, CDR-1: mild, CDR-2: moderate, and CDR-3: severe. The SCWT contains three parts in which SCWT$\mathrm{A}$ and SCWT-B measure attention and processing speed while SCWT-C mainly focuses on executive function [19]. In addition, other neuropsychological test including Activity of Daily Living (ADL), Neuropsychiatric Inventory (NPI), Hamilton Depression Rating Scale (HAMD), and Hachinski Ischemic Score (HIS) were also used to evaluate subjects' status. Demographic information such as age, sex, past history of diabetes mellitus, and current medication were collected at the same time.

Table 2. Comparison of cognitive function between MCI patients without diabetes and MCI patients with diabetes

\begin{tabular}{|c|c|c|c|}
\hline & $\begin{array}{c}\text { MCI } \\
\text { (non-diabetic) }\end{array}$ & $\begin{array}{c}\text { MCI } \\
\text { (diabetic) }\end{array}$ & $p$ \\
\hline & $n=65$ & $n=49$ & \\
\hline Recall in MMSE ( 3 words) & $2.04 \pm 0.84$ & $1.57 \pm 1.08$ & $0.020 *$ \\
\hline MMSE total score & $27.12 \pm 2.35$ & $25.84 \pm 3.58$ & 0.099 \\
\hline $\begin{array}{l}\text { AVLT immediate recall } \\
\text { (36 words) }\end{array}$ & $13.05 \pm 5.08$ & $10.89 \pm 3.87$ & 0.066 \\
\hline $\begin{array}{l}\text { AVLT } 5 \text {-minute recall } \\
(5 \mathrm{~min} / 12 \text { words })\end{array}$ & $3.55 \pm 2.83$ & $2.41 \pm 2.01$ & $0.031 *$ \\
\hline $\begin{array}{l}\text { AVLT long delay free recall } \\
(20 \mathrm{~min} / 12 \text { words })\end{array}$ & $3.03 \pm 2.79$ & $1.93 \pm 1.89$ & $0.049 *$ \\
\hline AVLT long delay cued recall & $0.55 \pm 1.31$ & $0.74 \pm 1.22$ & 0.379 \\
\hline SCWT-A performance time (s) & $30.86 \pm 10.77$ & $36.26 \pm 13.86$ & $0.035^{*}$ \\
\hline SCWT-A correct number $(50)$ & $49.13 \pm 3.07$ & $48.17 \pm 7.77$ & 0.750 \\
\hline SCWT-B performance time (s) & $45.56 \pm 13.38$ & $51.50 \pm 21.16$ & 0.253 \\
\hline SCWT-B correct number $(50)$ & $48.54 \pm 2.93$ & $44.73 \pm 10.98$ & $0.046^{*}$ \\
\hline SCWT-C performance time (s) & $91.47 \pm 36.3$ & $100.88 \pm 58.82$ & 0.688 \\
\hline SCWT-C correct number $(50)$ & $44.72 \pm 8.02$ & $43.18 \pm 9.56$ & 0.457 \\
\hline
\end{tabular}

MMSE = Mini-Mental State Examination;

AVLT $=$ Auditory Verbal Learning Test;

SCWT $=$ Stroop Color Words Test;

$\mathrm{MCI}=$ mild cognitive impairment subjects 


\section{Statistical analysis}

All data analyses were performed using SPSS. Independent samples $t$-test was applied to test inter-group differences in continuous variables while Chi square test was used for categorical variables. To assess correlations between the MMSE performance and the clinical characteristics, stepwise multiple regression was used. In order to investigate the differences between treatments, one-way analysis of variance (ANOVA) was applied in the three groups (with insulin treatment only, with oral anti-diabetic medication only, and with a combination of insulin with other diabetes medication). A $p$-value of less than 0.05 was considered significant.

\section{RESULTS}

\section{Comparison of cognitive function between subjects with and without diabetes}

In the normal cognitive function group, there was no significant difference in MMSE, AVLT, and SCWT between diabetic and non-diabetic subjects. However, MCI patients with T2DM demonstrated a worse performance vs non-diabetic MCI patients in these tests: recall of three words in MMSE ( $p=0.020)$, AVLT 5-minute recall $(p=0.031)$ and long delayed free recall $(p=0.049)$, the correct number of SWCT-B $(p=0.046)$ and performance time in SWCT-A (Table 2).

\section{Comparison of laboratory measures, genotyping and MR examination between subjects with and without cognitive impairment}

The plasma glucose and lipid concentrations, $A P O E \& 4$ genotyping as well as the brain MR examinations including IUD, ICW and IUD/ICW, showed no significant difference between normal cognitive function and MCI groups.

\section{Stepwise multiple regression model of MMSE scores}

Correlations between the MMSE score and diabetic duration, glucose and lipid metabolism were demonstrated in Table 3. The stepwise linear regression revealed that the better performance in MMSE was linked to lower $2 \mathrm{~h}-\mathrm{PG}$ (Coefficient $=-0.255, \mathrm{p}<0.001)$ and FCP (Coefficient $=-0.466, \mathrm{p}=0.001)$.

\section{Comparison of cognitive function of T2DM patients with different treatments}

We divided patients with T2DM into three groups: with insulin treatment only, with oral antidiabetic medication only, and a combination of insulin with other diabetes medication. To evaluate the performance in neuropsychological test of the three groups, we applied the one-way ANOVA test. As shown in Table 4, the difference in AVLT long delay cued recall between groups was significant $(p=0.002)$. Diabetic patients with a combination of insulin and other diabetes medication performed better in AVLT long delay cued recall $(p=0.001)$ compared to patients with insulin treatment only, and superior performance in AVLT long delay cued recall ( $p$ $=0.001)$, SCWT-B performance time $(p=0.049)$ and correct number $(p=0.009)$ vs patients with oral antidiabetic medication only. However, the outcome of patients with insulin treatment was only better than that of patients with oral antidiabetic medication in SCWT-B correct number $(p=0.018)$.

We further compared the results of T2DM patients with metformin medication and with sulphonylurea. We found that patients with metformin medication had a better memory outcome compared to patients with sulphonylurea medication in AVLT long delayed free recall $(p=0.010)$.

Table 3. Correlation between MMSE scores and clinical characteristics

\begin{tabular}{lcc}
\hline & Coefficient & $\boldsymbol{p}$ \\
\hline Duration & 0.216 & 0.966 \\
FPG & -0.029 & 0.449 \\
2h-PG & -0.255 & $<0.001^{*}$ \\
FINS & -0.090 & 0.993 \\
2h-INS & -0.127 & 0.939 \\
HbA1c & -0.264 & 0.257 \\
FCP & -0.466 & $0.001^{*}$ \\
TC & -0.111 & 0.780 \\
TG & -0.006 & 0.971 \\
HDL & -0.068 & 0.854 \\
LDL & -0.103 & 0.469 \\
\hline FPG $=$ fasting plasma glucose; \\
2h-PG = two hours postprandial plasma glucose; \\
FINS = fasting insulin; \\
2h-INS = two hours insulin; \\
HbA A $_{1}$ glycated hemoglobin; \\
FCP = fasting C-peptide; \\
TC = total cholesterol; \\
TG = triglyceride; \\
HDL = high-density lipoprotein; \\
LDL = low-density lipoprotein
\end{tabular}

\section{DISCUSSION}

A wide range of cognitive domains was reported to be impaired in older patients with T2DM, which has a close relation with the pathological mechanisms. Insulin and its signaling pathways not only regulate glucose and energy 
metabolism, but also modulate learning and memory [20]. As cognition-related structures such as the hippocampus and entorhinal cortex have a high density of insulin receptors and can produce insulin locally, an obstacle in any of the insulin signaling pathways can give rise to cognitive dysfunction most of which relates to memory, attention and executive functions [21, 22]. In addition, the evidence from neuroimaging also supports the view that T2DM impacts cognition. Using single photon emission computed tomography (SPECT) in elderly diabetic patients, it was reported that there is a reduction in cerebral perfusion of the fronto-temporal region, a region that plays an important role in memory, judgment, attention, learning ability and other functions [23]. Furthermore, a resting-state functional MRI study confirmed altered amplitude of low-frequency fluctuations (ALFF) in many brain regions of T2DM patients, which reflected poor neurocognitive performances [24]. Our study also found that MCI patients with T2DM had worse performances in memory, attention, and information processing speed. These results correlated with the acknowledged pathological mechanisms and neuroimaging.

Table 4. Comparison of cognitive functions between insulin, oral anti-diabetic therapy and combined therapy groups

\begin{tabular}{|c|c|c|c|c|}
\hline & $\begin{array}{c}\text { Insulin } \\
\text { treatment only }\end{array}$ & $\begin{array}{l}\text { Oral antidiabetic } \\
\text { medication only }\end{array}$ & $\begin{array}{l}\text { Combined } \\
\text { treatment }\end{array}$ & ANOVA \\
\hline Number & 12 & 59 & 9 & \\
\hline $\begin{array}{l}\text { AVLT immediate recall ( } 36 \\
\text { words) }\end{array}$ & $14.70 \pm 5.17$ & $12.83 \pm 5.03$ & $16.75 \pm 5.63$ & $\begin{array}{l}\mathrm{F}=2.406 \\
p=0.097\end{array}$ \\
\hline $\begin{array}{l}\text { AVLT } 5 \text {-minute recall } \\
(5 \mathrm{~min} / 12 \text { words })\end{array}$ & $3.90 \pm 3.28$ & $3.78 \pm 2.65$ & $5.25 \pm 2.86$ & $\begin{array}{l}\mathrm{F}=1.000 \\
p=0.373\end{array}$ \\
\hline $\begin{array}{l}\text { AVLT long delay free recall } \\
(20 \mathrm{~min} / 12 \text { words })\end{array}$ & $3.50 \pm 3.03$ & $3.33 \pm 2.70$ & $4.75 \pm 3.28$ & $\begin{array}{l}\mathrm{F}=0.905 \\
p=0.409\end{array}$ \\
\hline AVLT long delay cued recall & $0.40 \pm 0.70$ & $1.17 \pm 1.81$ & $3.38 \pm 2.26$ & $\begin{array}{l}\mathrm{F}=6.971 \\
* p=0.002\end{array}$ \\
\hline $\begin{array}{l}\text { SCWT-A } \\
\text { performance time (s) }\end{array}$ & $31.80 \pm 12.56$ & $32.20 \pm 12.11$ & $26.75 \pm 7.07$ & $\begin{array}{l}\mathrm{F}=0.729 \\
p=0.486\end{array}$ \\
\hline $\begin{array}{l}\text { SCWT-A } \\
\text { correct number (50) }\end{array}$ & $50.00 \pm 0.00$ & $48.72 \pm 6.80$ & $49.75 \pm 0.71$ & $\begin{array}{l}\mathrm{F}=0.260 \\
p=0.772\end{array}$ \\
\hline $\begin{array}{l}\text { SCWT-B } \\
\text { performance time (s) }\end{array}$ & $41.90 \pm 11.13$ & $47.96 \pm 18.95$ & $34.86 \pm 6.75$ & $\begin{array}{l}\mathrm{F}=2.286 \\
p=0.110\end{array}$ \\
\hline $\begin{array}{l}\text { SCWT-B } \\
\text { correct number (50) }\end{array}$ & $49.70 \pm 0.95$ & $46.52 \pm 7.73$ & $49.88 \pm 0.35$ & $\begin{array}{l}\mathrm{F}=1.556 \\
p=0.219\end{array}$ \\
\hline $\begin{array}{l}\text { SCWT-C } \\
\text { performance time (s) }\end{array}$ & $73.20 \pm 20.36$ & $92.83 \pm 50.35$ & $68.88 \pm 21.50$ & $\begin{array}{l}\mathrm{F}=1.547 \\
p=0.220\end{array}$ \\
\hline $\begin{array}{l}\text { SCWT-C } \\
\text { correct number (50) }\end{array}$ & $46.10 \pm 6.57$ & $44.10 \pm 8.95$ & $47.00 \pm 2.51$ & $\begin{array}{l}\mathrm{F}=0.595 \\
p=0.555\end{array}$ \\
\hline
\end{tabular}

Although there was no significant difference in glucose and lipid metabolism as well as brain imaging, the results of linear regression suggested that the level of FCP might influence cognitive function in patients with T2DM. $\mathrm{C}$-peptide is a link of $\mathrm{a}-\mathrm{b} \mathrm{b}$-chains of the insulin molecule. Neither liver enzymes nor external insulin will perturb the concentration of C-peptide in the blood. Thus, it has become a core intermediate product for the analysis of insulin release. However, recent studies revealed that Cpeptide is not restricted to its use in the measurement of insulin as it also plays important roles in a variety of physiological processes [25]. Through studying patients with type one diabetes mellitus (T1DM), C-peptide was found to be involved in inflammation, cognitive function, microcirculation and regulatory effects on various features such as neurotrophic factors, pain sensitivity and glomerular filtration [26]. Under physiological concentrations, C-peptide demonstrates its power in antiinflammatory, immunomodulatory and neuroprotective effects. Damage may occur in patients with T1DM due to the absence of C-peptide whereas those with T2DM may be harmed because of an excess of C-peptide, causing 
complications in cardiovascular and nervous systems [27, 28]. The finding in this study suggests that FCP is negatively correlated with the MMSE scores in patients with T2DM probably because of its underlying mechanism.

Meanwhile, the 2h-PG levels also showed a negative correlation with cognition function. Previously, a largesample perspective study with a median follow-up of 6.8 years suggested that higher average glucose levels were related to an increased risk of dementia [29]. The mechanism of this phenomenon revealed that hyperglycemia might cause an increasing risk of microvascular disease and structural changes in the hippocampus [30]. Besides, Morby [31] pointed out that even among the elderly population with higher-blood glucose levels in the normal range, the frontal cortex could be impacted to result in impairment in working memory, executive function, information processing speed and language. Another research focusing on the relationship between MCI and diabetes suggested an association of MCI with diabetes mellitus in the aspects of onset, duration and severity [32]. Both clinical and mechanistic studies provided clear clues that a better control in blood glucose is essential for the prevention of patients with T2DM from developing cognitive impairment. Our study, again, confirmed this viewpoint.

Will the different choice of treatment affect the cognitive function in patients with T2DM? Some previous literature reported that insulin therapy might slow down the decline of cognition in patients with T2DM [33]. For our study, however, better outcomes of cued recall, attention and information processing speed were witnessed in the combination-therapy group compared to oral antidiabetic medication group while patients with insulin treatment performed better than those with oral antidiabetic medication only in one of the tests for attention and information processing speed. Beeri and colleagues [34] reported in a postmortem study that lower neuritic plaque density in the hippocampus, entorhinal cortex, and amygdala was found in patients receiving a combination of insulin and other diabetes medication. This may explain the phenomenon in our study. In addition, patients with metformin medication exhibited a better memory outcome compared to patients with sulphonylurea medication. Metformin is known as one of the first line treatment for T2DM. Metformin improves glucose metabolism mainly by suppressing hepatic glucose production and altering pathways of insulin signaling [35]. It has been confirmed that metformin could cross the blood-brain barrier (BBB) then directly pose anti-inflammatory and neuroprotective effects on CNS [36]. Animal models also demonstrated that metformin effectively improves peripheral insulin sensitivity in rats under insulin resistant condition. Metformin was also shown to significantly decrease peripheral and brain oxidative stress levels and prevent brain mitochondrial dysfunction so that the learning behavior was improved in experimental rats [37].

In conclusion, our study found that for MCI patients, those with T2DM showed poor performance in cognitive functions, including attention, information processing speed and memory. Both $2 \mathrm{~h}-\mathrm{PG}$ and FCP had a negative correlation with cognitive function, indicating that cognitive function may deteriorate without a strict supervision of blood glucose and fasting C-peptide. In addition, patients treated with the combination therapy ended up with a better outcome in multiple cognitive domains compared to those treated with insulin only or oral antidiabetic medication only. Furthermore, in the oral antidiabetic medication group, patients with metformin medication had a better preservation of memory than those with sulphonylurea. Because of limited information from imaging in this study, we are looking forward to elaborate the difference in brain structure and function between patients with or without diabetes mellitus by functional magnetic resonance imaging (fMRI) in future.

\section{Acknowledgements}

The authors are grateful to all subjects who participated in this study and wish to acknowledge the valuable advice and assistance from the Department of Endocrinology as well as the specialized nurses and radiologic technicians.

\section{References}

[1] Ott A, Stolk RP, van Harskamp F, Pols HA, Hofman A, Breteler MM (1999). Diabetes mellitus and the risk of dementia: The Rotterdam Study. Neurology, 53: 19371942

[2] Velayudhan L, Poppe M, Archer N, Proitsi P, Brown RG, Lovestone S (2010). Risk of developing dementia in people with diabetes and mild cognitive impairment. The British journal of psychiatry : the journal of mental science, 196: 36-40

[3] Luchsinger JA, Reitz C, Patel B, Tang MX, Manly JJ, Mayeux R (2007). Relation of diabetes to mild cognitive impairment. Archives of neurology, 64: 570-575

[4] Cheng G, Huang C, Deng H, Wang H (2012). Diabetes as a risk factor for dementia and mild cognitive impairment: a meta-analysis of longitudinal studies. Internal medicine journal, 42: 484-491

[5] Kidd PM (2008). Alzheimer's disease, amnestic mild cognitive impairment, and age-associated memory impairment: current understanding and progress toward integrative prevention. Alternative medicine review : a journal of clinical therapeutic, 13: 85-115

[6] Samaras K, Sachdev PS (2012). Diabetes and the elderly brain: sweet memories? Therapeutic advances in endocrinology and metabolism, 3: 189-196 
[7] Sima AA, Kamiya H, Li ZG (2004). Insulin, C-peptide, hyperglycemia, and central nervous system complications in diabetes. European journal of pharmacology, 490: 187-197

[8] Martins IJ, Hone E, Foster JK, Sunram-Lea SI, Gnjec A, Fuller SJ, et al. (2006). Apolipoprotein E, cholesterol metabolism, diabetes, and the convergence of risk factors for Alzheimer's disease and cardiovascular disease. Molecular psychiatry, 11: 721-736

[9] Bornstein NM, Brainin M, Guekht A, Skoog I, Korczyn AD (2014). Diabetes and the brain: issues and unmet needs. Neurological sciences : official journal of the Italian Neurological Society and of the Italian Society of Clinical Neurophysiology, 35: 995-1001

[10] Umegaki H (2014). Type 2 diabetes as a risk factor for cognitive impairment: current insights. Clinical interventions in aging, 9: 1011-1019

[11] Alberti KG, Zimmet PZ (1998). Definition, diagnosis and classification of diabetes mellitus and its complications. Part 1: diagnosis and classification of diabetes mellitus provisional report of a WHO consultation. Diabetic medicine : a journal of the British Diabetic Association, 15: 539-553

[12] Petersen RC, Smith GE, Waring SC, Ivnik RJ, Tangalos EG, Kokmen E (1999). Mild cognitive impairment: clinical characterization and outcome. Archives of neurology, 56: 303-308

[13] Ma J, Zhou Y, Xu J, Liu X, Wang Y, Deng Y, et al. (2014). Association study of TREM2 polymorphism rs 75932628 with late-onset Alzheimer's disease in Chinese Han population. Neurological research: 1743132814Y0000000376

[14] Dahlbeck JW, McCluney KW, Yeakley JW, Fenstermacher MJ, Bonmati C, Van Horn G, 3rd, et al. (1991). The interuncal distance: a new MR measurement for the hippocampal atrophy of Alzheimer disease. AJNR. American journal of neuroradiology, 12: 931-932

[15] Mu Q, Xie J, Wen Z, Weng Y, Shuyun Z (1999). A quantitative MR study of the hippocampal formation, the amygdala, and the temporal horn of the lateral ventricle in healthy subjects 40 to 90 years of age. AJNR. American journal of neuroradiology, 20: 207-211

[16] Cui GH, Yao YH, Xu RF, Tang HD, Jiang GX, Wang Y, et al. (2011). Cognitive impairment using educationbased cutoff points for CMMSE scores in elderly Chinese people of agricultural and rural Shanghai China. Acta neurologica Scandinavica, 124: 361-367

[17] Guo Q, Zhao Q, Chen M, Ding D, Hong Z (2009). A comparison study of mild cognitive impairment with 3 memory tests among Chinese individuals. Alzheimer disease and associated disorders, 23: 253-259

[18] Morris JC (1993). The Clinical Dementia Rating (CDR): current version and scoring rules. Neurology, 43: 24122414

[19] Guo Q HZ, Lv C, et al. (2005). Application of Stroop color-word test on Chinese elderly patients with mild cognitive impairment and mild Alzheimer's dementia. Chin J Neuromed, 4: 701-704

[20] Zhao WQ, Alkon DL (2001). Role of insulin and insulin receptor in learning and memory. Molecular and cellular endocrinology, 177: 125-134

[21] Derakhshan F, Toth C (2013). Insulin and the brain. Current diabetes reviews, 9: 102-116

[22] Muller AP, Gnoatto J, Moreira JD, Zimmer ER, Haas CB, Lulhier F, et al. (2011). Exercise increases insulin signaling in the hippocampus: physiological effects and pharmacological impact of intracerebroventricular insulin administration in mice. Hippocampus, 21: 10821092

[23] Niwa H, Koumoto C, Shiga T, Takeuchi J, Mishima S, Segawa T, et al. (2006). Clinical analysis of cognitive function in diabetic patients by MMSE and SPECT. Diabetes research and clinical practice, $72: 142-147$

[24] Xia W, Wang S, Sun Z, Bai F, Zhou Y, Yang Y, et al. (2013). Altered baseline brain activity in type 2 diabetes: a resting-state fMRI study. Psychoneuroendocrinology, 38: 2493-2501

[25] Hills CE, Brunskill NJ (2009). Cellular and physiological effects of C-peptide. Clinical science, 116: 565-574

[26] Sima AA (2003). C-peptide and diabetic neuropathy. Expert opinion on investigational drugs, 12: 1471-1488

[27] Shpakov AO, Granstrem OK (2013). [C-peptide physiological effects]. Rossiiskii fiziologicheskii zhurnal imeni I.M. Sechenova / Rossiiskaia akademiia nauk, 99: 196-211

[28] Shpakov AO, Granstrem AO (2013). [C-peptide structure, functions and molecular mechanisms of action]. Tsitologiia, 55: 16-27

[29] Crane PK, Walker R, Larson EB (2013). Glucose levels and risk of dementia. The New England journal of medicine, 369: 1863-1864

[30] Kerti L, Witte AV, Winkler A, Grittner U, Rujescu D, Floel A (2013). Higher glucose levels associated with lower memory and reduced hippocampal microstructure. Neurology, 81: 1746-1752

[31] Mortby ME, Janke AL, Anstey KJ, Sachdev PS, Cherbuin N (2013). High "normal" blood glucose is associated with decreased brain volume and cognitive performance in the 60s: the PATH through life study. PloS one, 8: e73697

[32] Roberts RO, Geda YE, Knopman DS, Christianson TJ, Pankratz VS, Boeve BF, et al. (2008). Association of duration and severity of diabetes mellitus with mild cognitive impairment. Archives of neurology, 65: 10661073

[33] Plastino M, Fava A, Pirritano D, Cotronei P, Sacco N, Sperli T, et al. (2010). Effects of insulinic therapy on cognitive impairment in patients with Alzheimer disease and diabetes mellitus type-2. Journal of the neurological sciences, 288: 112-116

[34] Beeri MS, Schmeidler J, Silverman JM, Gandy S, Wysocki M, Hannigan CM, et al. (2008). Insulin in combination with other diabetes medication is associated with less Alzheimer neuropathology. Neurology, 71: 750-757

[35] He L, Sabet A, Djedjos S, Miller R, Sun X, Hussain MA, et al. (2009). Metformin and insulin suppress hepatic gluconeogenesis through phosphorylation of CREB binding protein. Cell, 137: 635-646 
[36] Labuzek K, Suchy D, Gabryel B, Bielecka A, Liber S, Okopien B (2010). Quantification of metformin by the HPLC method in brain regions, cerebrospinal fluid and plasma of rats treated with lipopolysaccharide. Pharmacological reports : PR, 62: 956-965

[37] Pintana H, Apaijai N, Pratchayasakul W, Chattipakorn N,
Chattipakorn SC (2012). Effects of metformin on learning and memory behaviors and brain mitochondrial functions in high fat diet induced insulin resistant rats. Life sciences, 91: 409-414 